tates the addition of lead ballast. The suit consists of a series of articulated sections having sliding or rotating joints, sealed sufficiently by means of leather and rubber packing; there are fifty-six of these flexible joints. Roller bearings working upon steel rings prevent jamming of the joints under high water pressure. The various parts of the suit are strengthened by internal and external ribbing. The diver in the Macduffee armour breathes air at ordinary atmospheric pressure, no matter how deep he goes, and this differentiates the new suit from the ordinary flexible diving dress. Every part of the diver is enclosed, anc' this necessitates the addition to the dress of ingenious mechanical hands operated from the interior of the dress. Dangerous accumulations of water due to leakage are dealt with by means of a small pump attached to the dress and worked by compressed air; suction pipes lead from the pump to each foot.

\section{GEOPHYSICAL MEMOIRS.'}

'THE reproach has frequently been levelled at meteorologists as a class that they are almost entirely devoted to the accumulation of masses of undigested and possibly indigestible data, but the aptness of the reproach has been steadily modified of late years, and one of the chief agencies in this country in producing this modification has been the activity of the reconstituted Meteorological Office, under the directorship of Dr. Shaw. When he was awarded the Symons gold medal by the Royal Meteorological Society, one of the grounds specifically mentioned as influencing the council in making the award was Dr. Shaw's capacity for suggesting fruitful lines of research for other people, and the memoirs contained in the volume now being completed bear testimony to this contention.

About ten years ago Dr. Shaw instituted fortnightly meetings during the winter session at the Meteorological Office, to which he invited people interested in meteorology and kindred subjects, and at which definite work on such subjects was discussed and freely criticised in an informal manner, and among the regular attendants at these meetings for some time past has been Mr. J. Fairgrieve, who, having sufficient spare time, amid scholastic duties, undertook the investigation which forms No. 9 of the Geophysical Memoirs. It is to be hoped that his example will be freely followed. No. Io is a more strictly "office" production, being the continuation of No. I, in which the superintendent of the Department of Marine Meteorology discusses the effect of the Labrador current year by year upon the surface temperature of the Atlantic and upon the meteorology of the British Isles.

It must be admitted that a considerable proportion of meteorological data is scarcely available for discussion, so that the first duty of the investigator is to sift his material and try to introduce homogeneity. For this reason pioneer work such as Mr. Fairgrieve's "On the Relation between the Velocity of the Gradient Wind and that of the Observed Wind," in which the data are numbers estimated on the Beaufort scale, is the more valuable, in that future investigators are given precious hints as to what to avoid, and observers may take notice of directions in

1 Meteorological Office. Geophysical Memoirs. Vol. i., Nos. 9 and ro, completing the first volume. No. 9. On the Relation between the Velocity of the Gradient Wind and that of the Observed Wind. Bv J. Fairgrieve. Pp. $189-207$.

No. 10. The Effect of the Labrador Current upon the Surface Tempera. ture of the North Atlantic, and of the latter upon Air Temperature and Pressure over the British I-les. Part ii. By. Commander M. W. C. Hepworth. Pp. 211-220. (London: Meteorological Office, 19:4.) Prict Is. and $8 d$. respectively.

$$
\text { NO. } 2358 \text {, VOL. 94] }
$$

which the form of their data can be improved. The conclusions are encouraging, and the plates of illustration interesting, although the most obvious deduction from them is simply that sea-winds predominate at coast stations, which is scarcely novel. It is evident that more work of the kind is needed, and equally evident that on this subject, as on many others, the proportion of chaff among the available data is inconveniently high. There is a valuable introductory note by Dr. Shaw, who takes the opportunity to print some tables of great wind pressures and velocities at the British stations in the twelve years I899-1910.

W. W. B.

\section{THE ARTIFICIAL PRODUCTION OF VIGOROUS TREES.}

I $\mathrm{N}$ an article on the artificial production of vigorous trees, contributed to the Journal of the Department of Agriculture and Technical Instruction in Ireland (No. I, October, I9I4) Prof. Augustine Henry discusses the nature of species, varieties, races, sports, and hybrids, as they appear to be from his researches. Natural species, in the case of trees, are readily recognised by the occurrence of each in a definite region or habitat. We have thus one species of silver fir in Central Europe, another in Algeria, a third in southern Spain, etc. Of our common trees-oak, birch, and elm-there are pairs of species in the same region, each, however, occupying a different habitat, one species adapted to a dry situation, the other suited to a moister soil. The pedunculate oak is a native of valleys and alluvial flats. It is not protected against evaporation of water, the supply of which in the ground it prefers being always ample. The sessile oak is a native of hilly and rocky districts, where water is not abundant in the soil. Its leaves are covered beneath with hairs, which guard against excessive loss of water by transpiration in windy weather. Similarly two alders exist on the Continent, but only one species, Alnus glutinosa, reached our islands, after the retreat of the ice sheet, and before the land connection with France was severed by the formation of the Straits of Dover. The other species, A. incana, grey alder, is absent from our native flora, but when introduced is very hardy, and is useful for planting in low-lying situations liable to spring frosts. The ash requires such special conditions of soil, that only one species exists in Northern and Central Europe, there being no suitable soil for a second species to inhabit.

A natural species is often a set of individuals uniform over a large area; but it may consist of two or more "geographical varieties," which correspond with distinct territories, each marked by slight differences of foliage, etc., that render the variety better fitted for its own habitat. Thus the Corsican and Austrian pines are closely related, but the latter keeps its leaves two years longer on the branches, so that the dense shade of its abundant foliage preserves moisture in the crevices of the hot limestone rocks, on which it grows in its Austrian and Servian home. The Corsican pine, with half the foliage of the other tree, thrives on granite soil in the moist insular climate of the mountains of Corsica. These two pines -only notably distinct in one character, the amount of their foliage-are usually regarded as two geographical varieties of the same species, Pinus Laricio, but by some botanists are considered to be two distinct species.

In a species apparcntly uniform over a large area there may exist varieties, characterised by minute and scarcely describable differences. This is exemplified 
by the Scots pine. Plots of its seedlings, raised from seed of trees in the forests of Scotland, Russia, Switzerland, etc., differ in vigour and in other respects (immunity to certain fungi, etc.), when all are grown together under identical conditions. Such varieties, with slight differences of structure, may be called races, and are of great practical importance in forestry. Only seeds of the best race, that is, from vigorous trees of the most suitable locality, should be used.

A sport is usually a solitary phenomenon, arising either as a sporadic peculiar seedling from a seed, or developing out of a bud on a tree as a single branch with some peculiarity of twig or leaf. A sport may be looked upon as a freak, not forming the starting point of a new species, but speedily becoming extinct if left to nature. Sports, when of interest on account of the curiosity or the beauty of their appearance, are propagated usually by grafts, cuttings, or layers; being only in rare cases perpetuated by seed. Some sports are due to arrested development. The tree, in the course of its life, often passes through stages, like those of an insect. The seedling of many species differs from the adult tree as a larva from a butterfly. The infant ash has simple leaves. The

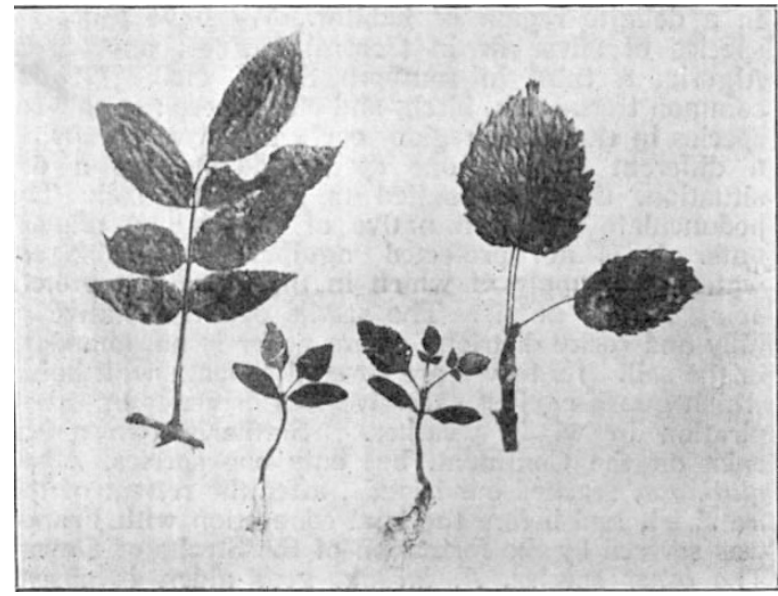

FIG. t. -Adult foliage of common ash on leit, of simple-leaf ash on right; two ash seedlings in the middle, showing primary leaves above the pair of cotyledons.

sport known as the simple-leaf ash is simply a seedling ash, which has never progressed to maturity and may be called a persistent larval form (Fig. I).

Abnormal colouring of leaves, so-called variegation, is a sport, usually starting as a solitary branch on an otherwise normal tree, which, when noticed, is propagated by grafting. Deeply-lobed, crumpled, pitcherlike, and other abnormal leaves occur in many species, and are propagated as curiosities. In sports, reversion is often seen; thus on a fern-leaf beech one or two branches with normal leaves are not uncommon. This reversion may be due to the influence of the stock, as these sports are usually grafted; or it may be explained as the triumph locally of normal over abnormal factors. Such reversions are never seen in hybrid trees. The occurrence of a sport seems to predispose to further sporting; a tree with leaves abnormal in shape will sometimes take on, in one branch, abnormal colour as well. These double sports are common in the holly.

Hybrids are combinations of two species or of two varieties, which arise either in the wild state or in cultivation. They are met with in nature as rare individuals on the boundary line between the areas NO. 2358, VOL. 94$]$ occupied by two species. This is well seen in York shire, where a hybrid oak is found in the localities in which the sessile oak of the hills comes in contact with the pedunculate oak of the valleys. Hybrids arise frequently in nurseries, gardens, and parks, where several species are cultivated together.

Hybrid trees are more common than has been supposed. Many valuable trees, the real history of which has not been suspected by botanists, are of hybrid origin. As an example, may be mentioned the fine elm, which is universally planted in Holland and Belgium, where it is known as orme gras or Ulmus latifolia, Poederlé. This is not, as sometimes imagined, a natural species peculiar to those countries. It is unquestionably a hybrid, which is invariably propagated by layers, all the individual trees on this account being uniform in appearance. It seems to have originated three or four centuries ago, probably as a single seedling, which has given rise by vegetative reproduction since to millions of descendants.

The distinction between sports and hybrids is well

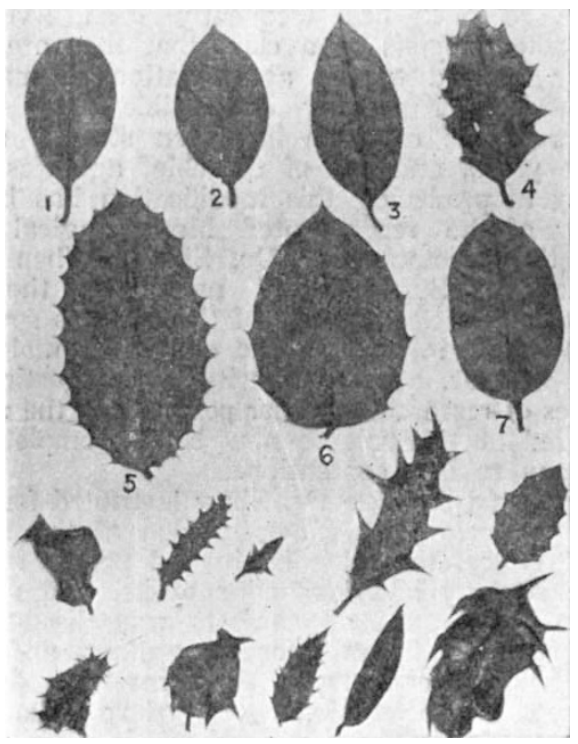

Fir. 2.-Holly. Species:-1. Ilex rerado; 2. I. Balearica: 3, 4. I. Aquifolium (native). Hybrids :-5. Sports:-The leaves not numbered are those of different sports of the native holly.

known in the numerous so-called "varieties" of the holly (Fig. 2). Some are sports of Ilex Aquifolitm, our native holly; others are hybrids, one parent being the common holly, whilst the other is either Ilex Perado, which was introduced from Madeira in $I 760$, or Ilex Balearica, the holly of the Balearic Isles, which was cultivated at Versailles in I789. Miller, in his account of the hollies in $175^{\circ}$, was acquainted only with the sports, which had arisen from the common holly, as the other species had not been introduced at that time and hybridisation was impossible. The hybrids originated soon after I80o, the earliest apparently being Ilex Hodginsi and Ilex Hendersoni, which were found by Hodgins as seedlings in his nursery at Dunganstown, Wicklow. Here Ilex Perado was cultivated; and old specimens producing flowers and fruit freely are still common in Wicklow gardens. The holly hybrids are vigorous trees, bearing large leaves intermediate between the parent species. The sports of the common holly are always gratted, and are feeble in growth, with a tondency for single branches to revert occasionally to the normal form. 
With regard to hybrids, Prof. Henry, by historical research and experiment, has established the fact that many fast-growing trees in cultivation as the Lucombe Oak, Common Lime, Cricket Bat Willow, Black Italian Poplar, etc., are hybrids. By artificial pollination (Fig. 3) he has succeeded in raising new hybrids,

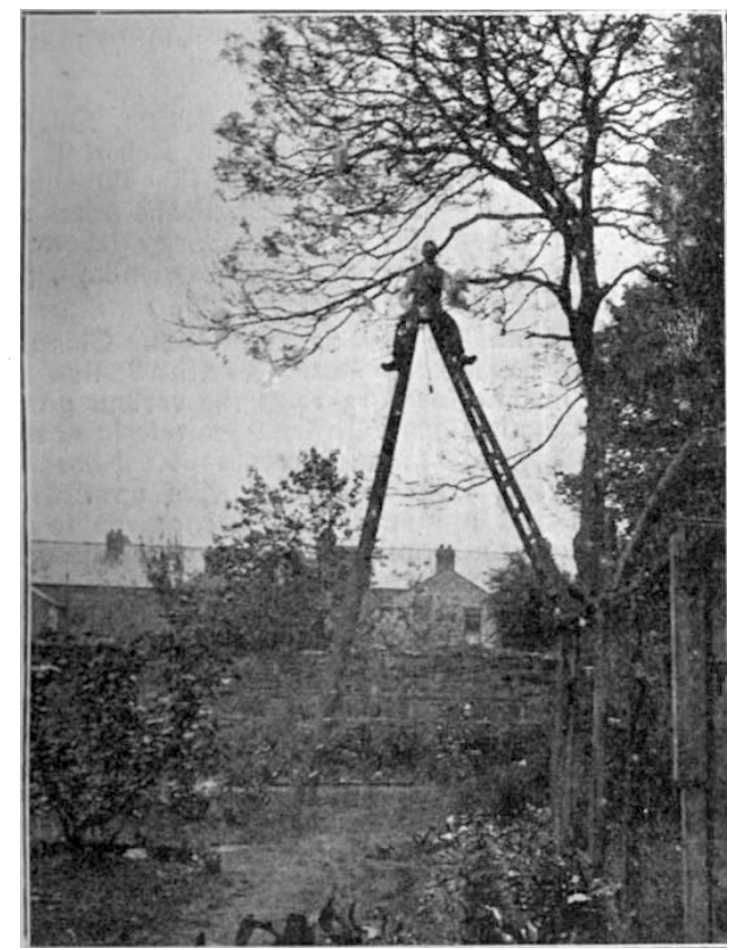

FIG. 3.-Cross-fertilising a walnut tree. The bags are on the branches above and to the left of the operator.

which display the extraordinary vigour characteristic of the first generation cross; and in his paper gives an account of these. The most notable so far are a new hybrid Poplar (Populus generosa) and crosses between the Common Ash and American species of Fraxinus.

\section{OPTICAL GLASS AND SCIENTIFIC INSTRU- MENTS: UNITED KINGDOM IMPORTS AND GERMAN EXPORTS.}

$\mathrm{N}$ reply to a request for information upon the subject of imports of optical glass and scientific instruments from Germany and elsewhere, the Commercial Intelligence Branch of the Board of Trade has favoured us with a statement showing the imports of scientific instruments and apparatus and parts into the United Kingdom in 1913 , distinguishing principal countries whence consigned. We have received, in addition, a statement of the German exports of optical glass and glass instruments in 1912 , distinguishing, inter alia, the exports to the United Kingdom, as well as particulars of the exports from Germany to the United Kingdom in I9I2 of other scientific instruments. As these particulars are of interest and importance at the present time, in connection with efforts being made to provide for increased supplies of optical and chemical glass and scientific instruments from manufacturers in the United Kingdom, No. 2358, VOL. 94] they are here reprinted by permission of the Board of Trade.

Imports of Scientific Instruments and Apparatus AND PARTS INIO THE UnITED KINGDOM IN I913. Extracted from the "Annual Statement of Trade OF THE UNITED KINGDOM."

Scientific Instruments and Apparatus (other than Electrical) Complete.

Total imports ...

$\begin{array}{cccr}\text { Of which from Germany } & \ldots & \text { GI0,34I } \\ & \text { Belgium } & \ldots & 362,89 \text { I } \\ & \text { France } & \ldots & 28,939 \\ & \text { Switzerland } & \ldots & \text { ro8,040 } \\ & \text { U.S.A. } \ldots & \ldots & \text { I } 92,872 \\ & & \end{array}$

Parts thereof (including Kinematograph Films, Photographic Plates, and Films and Sensitised Photographic Paper).

\begin{tabular}{|c|c|c|c|}
\hline Total imports & & ... & $2,373,426$ \\
\hline Of which from & Germany & $\cdots$ & 310,229 \\
\hline & Belgium & $\ldots$ & 126,725 \\
\hline & France & & 522,682 \\
\hline & Switzerland & 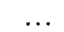 & 28,762 \\
\hline & Italy $\quad \ldots$ & $\cdots$ & I 2 I , 842 \\
\hline & U.S.A. ... & & $1,25^{6,3}$ \\
\hline
\end{tabular}

Exports of ScIEntific Instruments (OTHER THAN GLaSS) From GERMANY TO THE UNITED Kingdom IN rgi2. Extracted from the Officlal German Trade RETURNS.

Optical measuring instruments (polariscopes, etc.) nautical compasses, astronomic telescopes, and other astronomic, geodetic, rookilogs Marks nautical, etc., instruments $\quad . .887 \quad 317,000$

Pedometers, pocket instruments for recording, etc., automatic measuring and registering apparatus, speed indicators, automatic balances, etc. ... $\ldots$... ruling pens, mathematical instruments, etc. $\ldots \quad \ldots \quad \ldots$ Calculating machines $\quad \ldots . \quad \ldots$ Surgical instruments $\ldots$
Precision balances, instruments for Precision balances, instruments for
metrology and gauging barometric, calorimetric, thermometric, and chemical instruments $453 \quad 402,000$ $\begin{array}{llrr}\text { Physical teaching apparatus } \quad \ldots & 75 & 67,000\end{array}$ I00 kilogs. $=220.46 \mathrm{lb}$. Mark $=$ I $1.8 \mathrm{~d}$.

Exports of Optical Glass and Glass Instruments in I9I2, Distinguishing Principal Destinations. Extracted From the OfFicial German Trade RETURNS.

Terrestrial Telescopes, Opera Glasses of all Kinds.

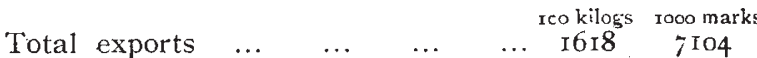

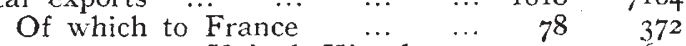

United Kingdom... $132 \quad 695$

$\begin{array}{lllll}\text { Italy } & \ldots & \ldots & \text { I } 40 & 534\end{array}$

$\begin{array}{rrrrr}\text { Austria } & \cdots & \cdots & \text { 190 } & 534 \\ & \cdots & \cdots & \text { I9I } & \text { 1034 }\end{array}$

$\begin{array}{lllll}\text { Russia } & \cdots & \cdots & 191 & 1034 \\ & \cdots & \cdots & 390 & 1686\end{array}$

Switzerland $\quad \ldots .67964$

$\begin{array}{lllll}\text { Turkey } \quad \ldots & \ldots & 55 & 2 \mathrm{I} 2\end{array}$

United States $\quad \ldots \quad$ I02 273 